\title{
DROUGHT EVALUATION WITH NDVI-BASED STANDARDIZED VEGETATION INDEX IN LOWER NORTHEASTERN REGION OF THAILAND
}

\author{
Tanutdech ROTJANAKUSOL ${ }^{1}$, Teerawong LAOSUWAN ${ }^{1 *}$
}

DOI: 10.21163/GT_2019. 141.09

\begin{abstract}
:
Drought is a natural phenomenon that usually occurs in various areas of the northeastern part of Thailand and it has a major impact on agriculture. The main objective of this studywas to apply remote sensing technology and the Standardized Vegetation Index (SVI) for the evaluation of drought in the aforementioned areas. For the implementation, data of the Normalized Difference Vegetation Index (NDVI) from the Terra/MODIS satellite was utilized for the analysis in order to examine the drought areas due to the change of the vegetation conditions by the SVI within a period of three years: 2014, 2015, 2106. According to the study, it was found that the worst drought was in 2016, followed by the years 2014 and 2015, respectively. Furthermore, for the reliability of this technique, the analysis results from the SVI to find the statistical relationship with the rainfall in the target areas was completed. The results of both sets of the data showed a high relationship in all three years $\left(2014, \mathrm{R}^{2}=0.83 ; 2015, \mathrm{R}^{2}=0.88\right.$ and $\left.2016, \mathrm{R}^{2}=0.97\right)$. Thus, it could be concluded that examining the drought situation by remote sensing technology and the SVI at different periods in the areas of the Lower Northeastern region of Thailand could identify the forms of drought effectively.
\end{abstract}

Key-words: Drought Evaluation, Remote Sensing, NDVI, SVI.

\section{INTRODUCTION}

The current issue found in Thailand the most is drought on account of less rain than usual or because of a dry spell. That is to say, the amount of continuous rainfall is less than $1 \mathrm{~mm}$ over a period of 15 days. This has a direct impact on agriculture and most water sources; therefore, drought causes major losses; e.g., dry soil, blocked plant growth, reduction of products, low quality products, and low product quantities (Gomasathit et al., 2013; Nistor et al., 2018). Generally, a drought arises from the lack of seasonal rain, but there are also other causes: for example, natural causes owing to a dry spell and less rainfall: low moisture storage capability of the soil: deforestation: lower amounts of water in reservoirs due to water exploitation: greenhouse effects, and industrial development. Thus, drought is not a result of a single cause (Laosuwan et al., 2016; Uttaruk \& Laosuwan, 2017).

In Thailand, the drought as mentioned appears annually, especially in winter to summer, starting from the middle of October onward. The rainfall reduces gradually until the rainy season returns again in mid-May of the following year. Then, it appears again in the middle of the rainy season due to a dry spell, around the end of June to July (Mongkolsawat et al., 2001). Rainfall is, a key factor that should be taken into

\footnotetext{
${ }^{1}$ Department of Physics, Faculty of Science, Khamriang Sub-District, Kantarawichai District, Maha Sarakham 44150,tanutdech.r@msu.ac.th.*corresponding author: teerawong@msu.ac.th
} 
consideration and examined to find out the relationship with the vegetation index, as well as to explore the rainfall periods affecting vegetation. The relationship between the vegetation index and rainfall is a crucial variable to determine the drought areas (Wattanakij \& Mongkolsawat, 2008). The application of remote sensing technology based on data from satellites for examining irregular drought areas is another technique that reflects vegetation change. That is because recorded data from satellites can be continuously repeated and can monitor real-time spatio-temporal change of land cover (Mongkolsawat et al., 2009; Seekaw et al., 2014; Kogan, F., \& Guo, 2015). When that data is brought for digital image processing together with mathematical statistics, the issue to be studied will be clarified; e.g., the Normalized Difference Vegetation Index (NDVI) calculation (Costea and Haidu, 2010; Costea et al., 2012). The results of the NDVI perfectly exhibit changes in the condition of the vegetation in each weather period (Tucker, 1979; Malo \& Nicholson, 1990; Peters et al., 2002; Gessner et al., 2013; Furtuna et al., 2015; Furtuna et al., 2018; Wang et al., 2013; Wu, et al., 2013; Vrieling et al., 2014).

Therefore, drought is a spatial issue, and data from satellites for examining drought in risky areas can raise better effectiveness of displaying the status of the issue. Hence, this study aimed to apply remote sensing technology and the Standardized Vegetation Index (SVI) for the evaluation of drought in areas of the Lower Northeastern region of Thailand.

\section{STUDY AREAS}

This study selected the implementation areas in the Lower Northeastern region of Thailand (Fig.1). They were divided into:

(1) The Lower Northeastern provincial cluster 1 consisting of four provinces; i.e., Nakhon Ratchasima, Chaiyaphum, Buri Ram, and Surin. The size of the area was 52,389.89 $\mathrm{km}^{2}$ or $30.83 \%$ of the total area of the Northeast, and $7.70 \%$ of the country.

(2) The Lower Northeastern provincial cluster 2 comprising four provinces; i.e., Ubon Ratchathani, Sisaket, Amnat Charoen, and Yasothon. The size of the area was 31,907.74 $\mathrm{km}^{2}$ or $18.89 \%$ of the total area of the Northeast, and $6.2 \%$ of the country.

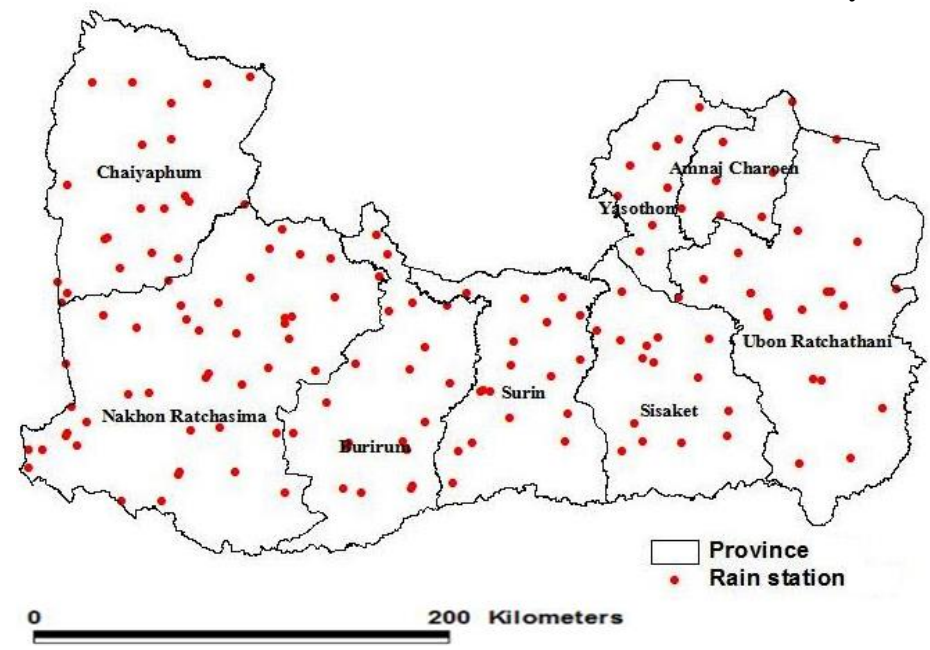

Fig. 1. Study area. 


\subsection{Data}

\subsubsection{Data from Terra/MODIS}

The Terra/MODIS satellite was designed for monitoring and examining natural resource data. The width of the swath was approximately $2,330 \mathrm{~km}$., with the resolutions from 250 to $1000 \mathrm{~m}$. and a 36-band record system. Data from the satellite, therefore, was most suitable for monitoring spatial change of vegetation. That was why the MOD13Q1 package (NDVI) was utilized in the study.

\subsubsection{Data from rainfall}

The data of the average monthly rainfall were collected from the rainfall station of the Thai meteorological staion (Fig.1 shows 154 station located in the Lower North-eastern region) for the period 2014-2016.

\section{METERIAL AND METHOD}

The implementation procedures were set as demonstrated in Fig. 2.

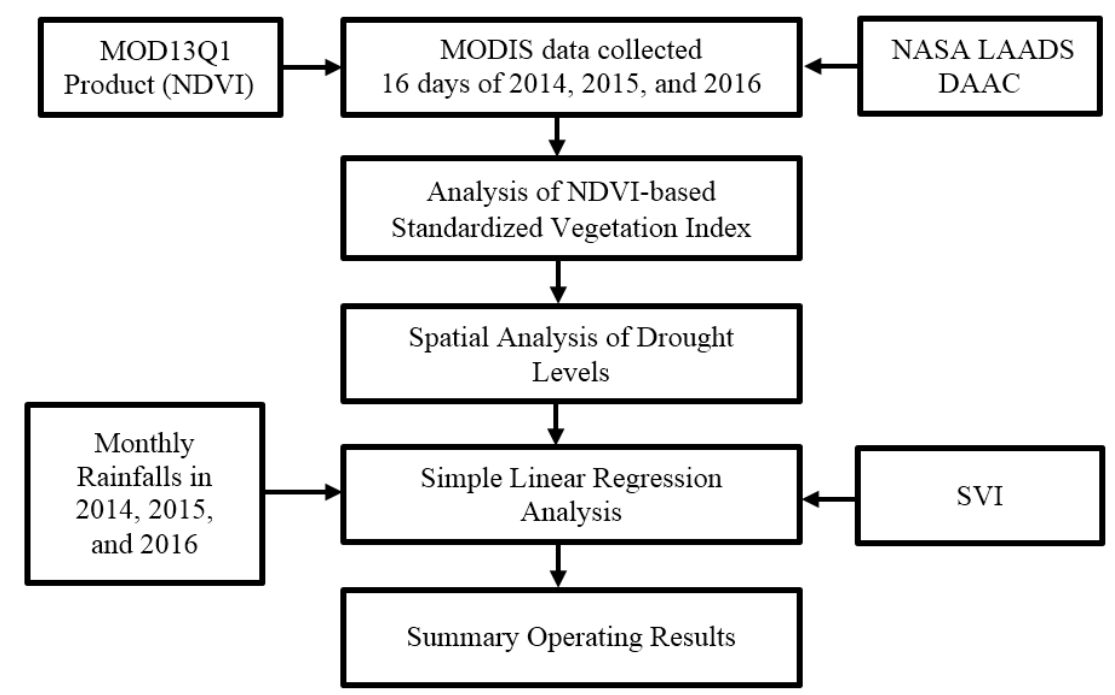

Fig. 2. Implementation procedures.

\subsection{Analysis of Terra/MODIS}

The Terra/MODIS satellite was designed for monitoring and examining natural resource data. The width of the swath was approximately $2,330 \mathrm{~km}$., with the spatial resolutions from 250 to $1000 \mathrm{~m}$. and a 36-band record system. The data from the satellite was most suitable for monitoring spatial change. That was why the MOD13Q1 package (NDVI) was utilized in the study. The data were collected from the Terra/MODIS satellite (January-December) during 2014-2016. It was downloaded from LAADS DAAC via https:// ladsweb.modaps.eosdis.nasa.gov/ and using MODIS Conversion Toolkit (plugin for ENVI program) for georeference data. 


\subsection{Rainfall analysis}

The data of the average monthly rainfall were collected from the rainfall station of the Meteorological Department, Thailand (particularly the station located in the Lower Northeastern region) for the period 2014-2016.

\subsection{SVI analysis}

Because the SVI depended on a z-score in each pixel of the data from the Terra/MODIS, the Z-score was to find the standard deviation (SD) from the mean in the unit of the SD, which was calculated from the NDVI of each pixel in each season. The study was separated into the three seasons of Thailand; namely, summer (17 February-16 May); rainy season (17 May-16 October), and winter (17 October-16February(. The z-score was analyzed as shown in Equation 1 (Peters et al., 2002; Laosuwan et al., 2016).

$$
Z_{i j k}=\frac{N D V I_{i j k}-\overline{N D V I_{i j}}}{\sigma_{i j}}
$$

Where;

$Z_{i j k}=$ the $\mathrm{z}$-value for pixel $\mathrm{i}$ during week $\mathrm{j}$ for year $\mathrm{k}$

$N D V I_{i j k}=$ the weekly NDVI value for pixel i during week $\mathrm{j}$ for year $\mathrm{k}$

$\overline{N D V I_{i j}}=$ the mean NDVI for pixel $\mathrm{i}$ during week $\mathrm{j}$ over $\mathrm{n}$ years and

$\sigma_{i j}=$ the standard deviation of pixel i during week $\mathrm{j}$ over $\mathrm{n}$ years

According to Equation 1, $\mathrm{Z}_{\mathrm{ijk}}$ was the hypothesis value in order to conform with the standard normal distribution $(\overline{\mathrm{x}}=0, \mathrm{SD}=1)$ for the test of the hypothesis from every pixel in each season for the period of 2014-2016. There was the probability of SVI = P) $Z_{\mathrm{ijk}}$ ( of the z-score from the NDVI. To reflect the probability of the possible vegetation conditions, the SVI analysis could be done as shown in Equation 2 (Peters et al., 2002; Park et al., 2008; Zhang et al., 2013).

$$
S V I=\frac{\left(Z_{i j k}-Z_{i j M I N}\right)}{Z_{i j M A X}-Z_{i j M I N}}
$$

Where;

$$
\begin{aligned}
& Z_{i j k}=\mathrm{z} \text {-value for pixel } \mathrm{i} \text { during week } \mathrm{j} \text { for year } \mathrm{k} ; \\
& Z_{i j M A X}=\text { maximum of } \mathrm{z} \text {-value for pixel } \mathrm{i} \text { during week } \mathrm{j} \text { and } \\
& Z_{i j M I N}=\text { minimum of } \mathrm{z} \text {-value for pixel i during week } \mathrm{j}
\end{aligned}
$$

According to Equation 2, the probability of each pixel was displayed as the SVI, which helped view the vegetation verdancy in terms of the probability of each pixel in all seasons in the different periods. The study focused on a period of three years (2014-2016) in order to present the comparison between the high and low levels of the drought within the fixed periods of the seasons. This was to estimate the probability of the current vegetation based on the past. The SVI was more than 0 but less than 1$) 0<$ SVI $<1(.0$ was the minimum zscore of the NDVI at the pixel of a certain period whereas 1 was the maximum z-score of the NDVI at the pixel of a certain period (Peters et al., 2002; Zhang et al., 2013). 


\subsection{Spatial analysis of the drought areas}

This was the classification based on monthly vegetation density in the aforementioned period. From the SVI, the study classified the drought into five levels )Table 1). 0.00-0.05 represented the very poor vegetation density (worst drought) whereas 0.95-1.00 represented a very good vegetation density (minimum drought) (Peters et al., 2002).

Table1.

The vegetation levels.

\begin{tabular}{cc}
\hline SVI level & Vegetation density \\
\hline $0.95-1.00$ & very good \\
$0.75-0.95$ & good \\
$0.25-0.75$ & average \\
$0.05-0.25$ & poor \\
$0.00-0.05$ & very poor \\
\hline
\end{tabular}

\subsection{Statistical relationship analysis}

For the reliability of the data analyzed from the SVI, the study brought the analysis results from the SVI to find the statistical relationship in the form of a linear regression analysis with monthly rainfalls in the three-year period.

\section{RESULTS AND DISCUSSIONS}

\subsection{Variation of SVI}

For the results of the monthly SVI variation in the three seasons; i.e., summer, rainy, and winter, the means of the SVI in all three seasons (2014-2016( are shown in Fig. 3. The graphs signified the SVI variance in each period of each year.

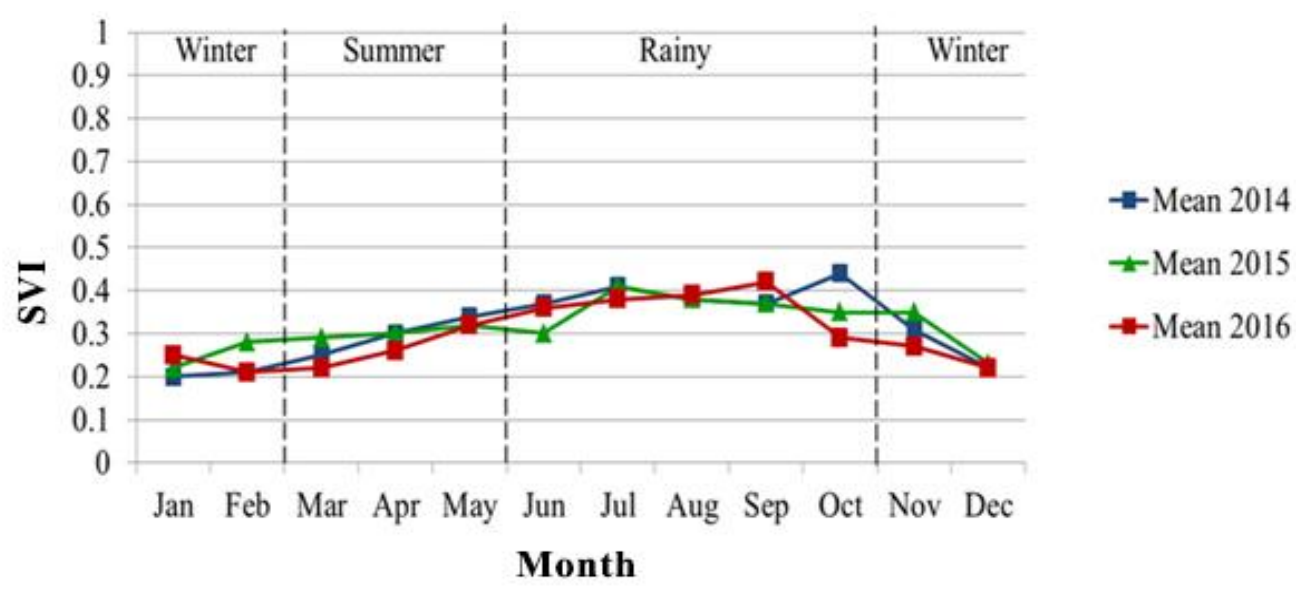

Fig. 3. Comparison of SVI in 2014-2016. 
From Fig. 3, the average indicated vegetation or drought condition in each period and each season. The result displayed that the year 2014 had the maximum average of 0.44 in October in the rainy season, and the minimum in 0.22 in December at the cold season. The year 2015 had the maximum average of 0.41 in July in the rainy season, and the minimum in 0.23 in December at the cold season. The year 2016 had the maximum average of 0.42 in September in the rainy season, and the minimum $t$ in 0.22 in December at the cold season.

\subsection{The drought areas}

According to the examination of drought by Terra/MODIS based on the SVI technique, it was found that the SVI variance in each period was caused by the amount of rainfall that was the determinant of the drought. The comparison of the SVI data of the different periods in each year revealed various changing vegetation conditions. The SVI spatial data obviously mirrored the different levels of the vegetation conditions. The spatial analysis of the drought areas in the three years is shown in Figs. 4-6.

According to Fig. 4 with respect to the areas in 2014, the condition of the vegetation was found to have a minimum during summer in March (SVI average $=0.20$ ) with the maximum distribution in May (SVI average $=0.34$ ) ; had a minimum during the rainy season in June (SVI average $=0.37$ ) and increased to its maximum in September (SVI average $=0.44$ ), and had a high spatial distribution during winter in November (SVI average $=0.31)$ and started to decline until December $($ SVI average $=0.22$ ).

According to Fig. 5 with respect to the areas in 2015, the condition vegetation was found to have a minimum during summer in April (SVI average $=0.30$ ) with the maximum distribution in May (SVI average $=0.32$ ); had a minimum during the rainy season in June $(\mathrm{SVI}$ average $=0.30)$ and increased to its maximum in July (SVI average $=0.41)$, and had a high spatial distribution during winter in November SVI average $=0.35$ ) and started to decline until December (SVI average $=0.23$ ).

According to Fig. 6, with respect to the areas in 2016, the condition of the vegetation was found to have a minimum during summer in March (SVI average $=0.22$ ) with the maximum distribution in May (SVI average $=0.26$ ); had a minimum during the rainy season in June (SVI average $=0.30$ ) and increased to its maximum in September (SVI average $=0.42$ ), and had a high spatial distribution during winter in November (SVI average $=0.27$ ), and started to reduce until December $($ SVI average $=0.22$ ).

For this study, the annual spatial SVI analysis was conducted for the annual spatial result displayed by overlaying the based on monthly data. The annual SVI results gave a more vivid expression of the spatio-temporal drought than the monthly ones. Fig. 7 clearly demonstrates that there was the maximum spatial drought (SVI annual averages data from 12 months) in 2016 , followed by 2014 and 2015, respectively.

\subsection{Statistical relationship analysis}

The analysis of the monthly means of the SVI in all three periods and the rainfall illustrated the conformity of the SVI. The relationship of the statistics, the SVI, and the rainfall was shown in Fig. 8-10. In Fig. 8, focusing on 2014, the statistical relationship analysis between the SVI and the rainfall generated the relationship equation as $\mathrm{y}=$ 1242.97x - 261.55, and $\mathrm{R}^{2}=0.83$. In Fig. 9, focusing on 2015, the statistical relationship analysis between the SVI and the rainfall generated the relationship equation as $y=1441.9 x$ -349.08, and $\mathrm{R}^{2}=0.88$. In Fig. 10, focusing on 2016, the statistical relationship analysis between the SVI and the rainfall generated the relationship equation as $\mathrm{y}=1420.54 \mathrm{x}-$ 306.57 , and $\mathrm{R}^{2}=0.97$. 


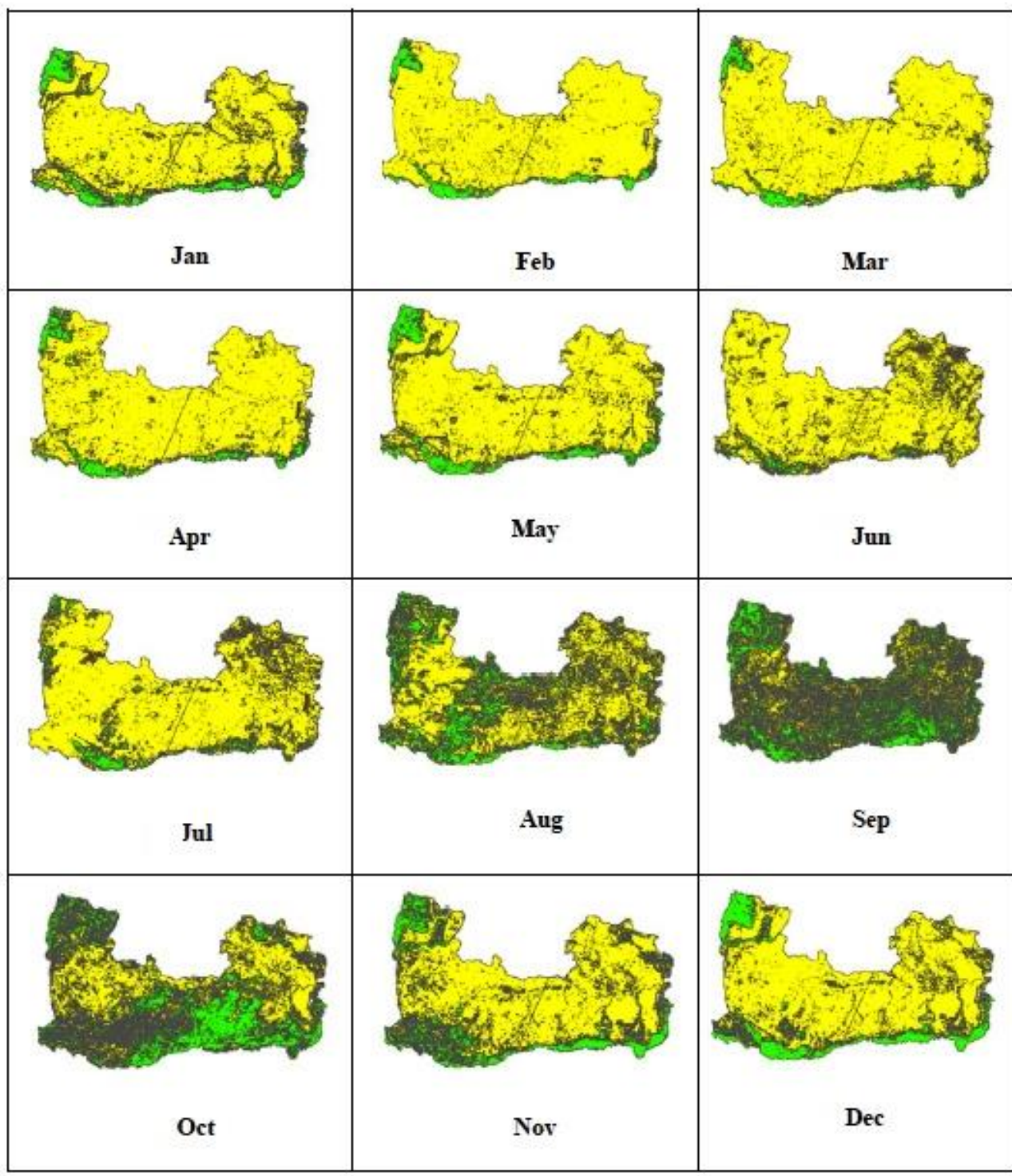

0.00-0.05

0.05-0.25

0.25-0.75

0.75-0.95

0.95-1.00

200 Kilometers

Fig. 4. Spatial analysis of vegetation conditions in 2014 . 


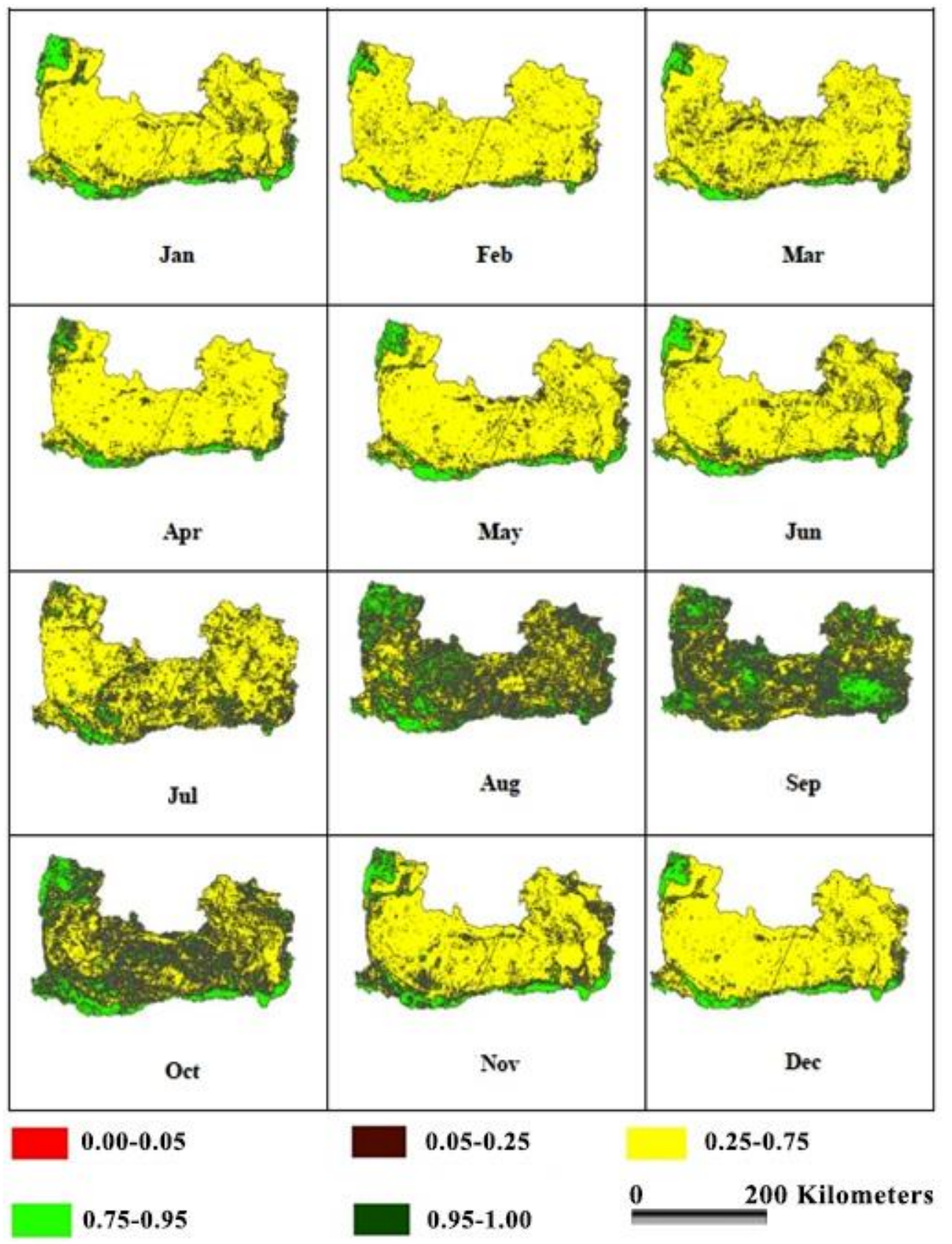

Fig. 5. Spatial analysis of vegetation conditions in 2015. 


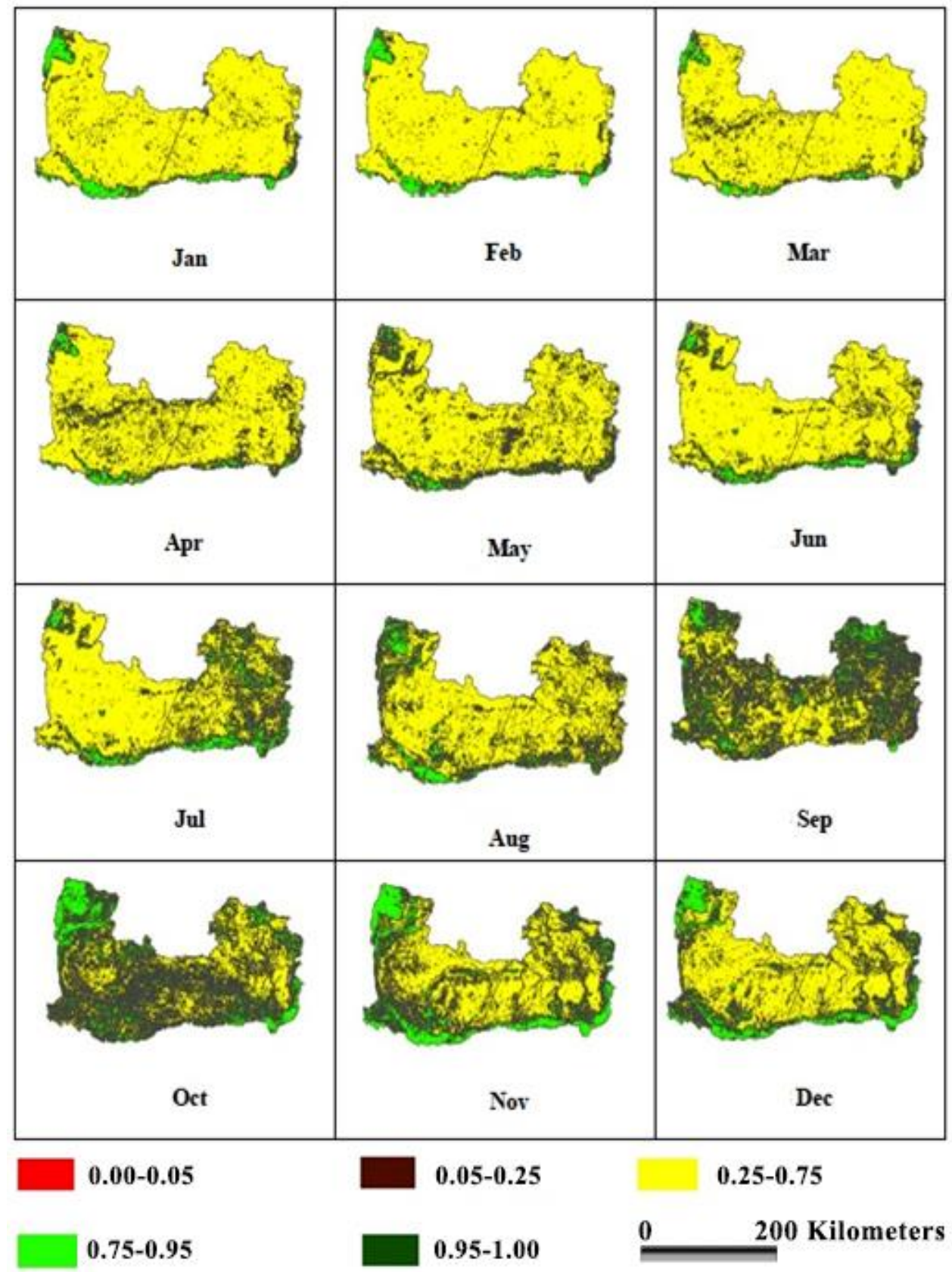

Fig. 6. Spatial analysis of vegetation conditions in 2016 . 


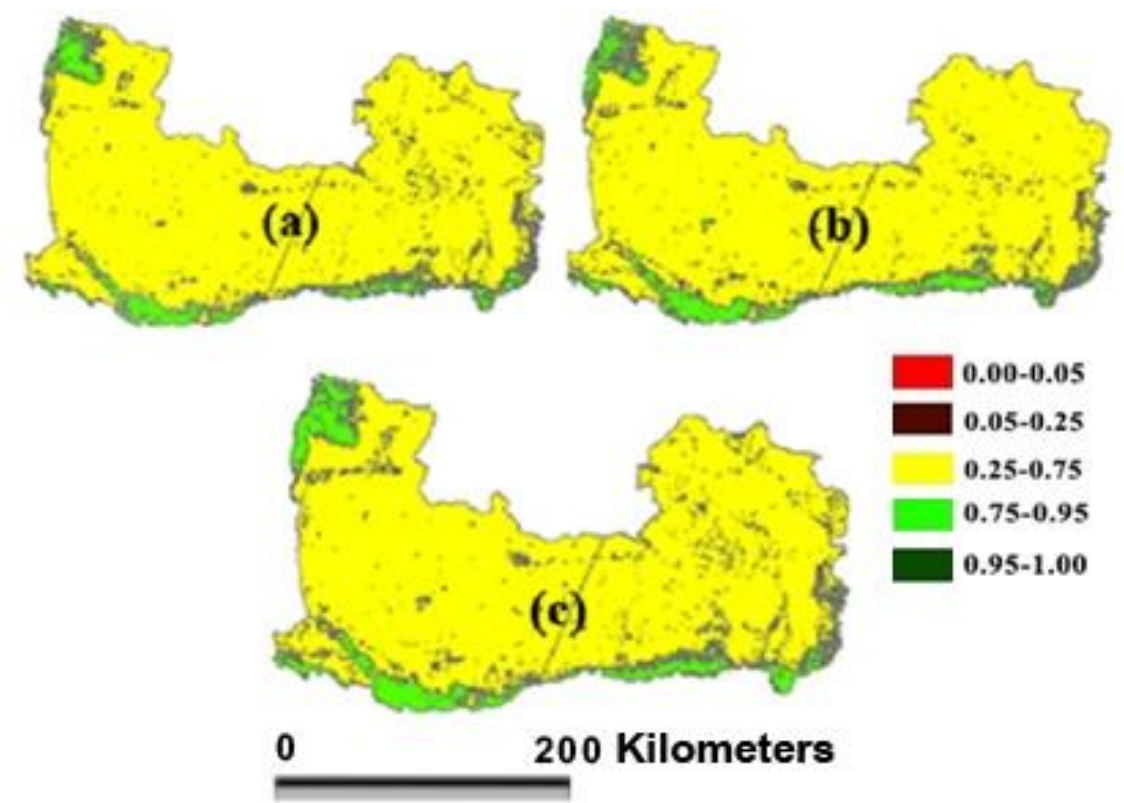

Fig. 7. Spatial analysis (a) 2016 (b) 2014 and (c) 2015.

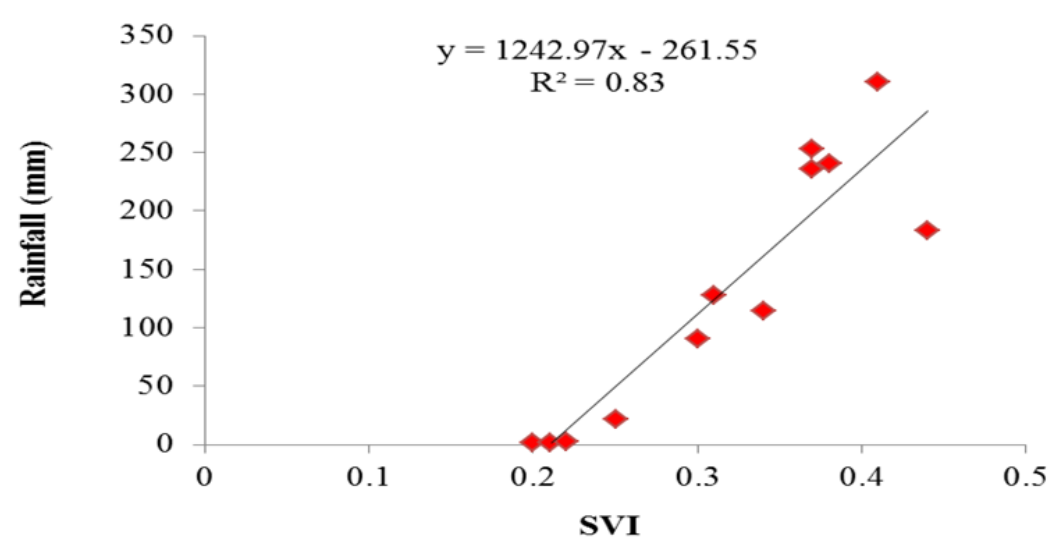

Fig. 8. Relationship of SVI and rainfall data in 2014 


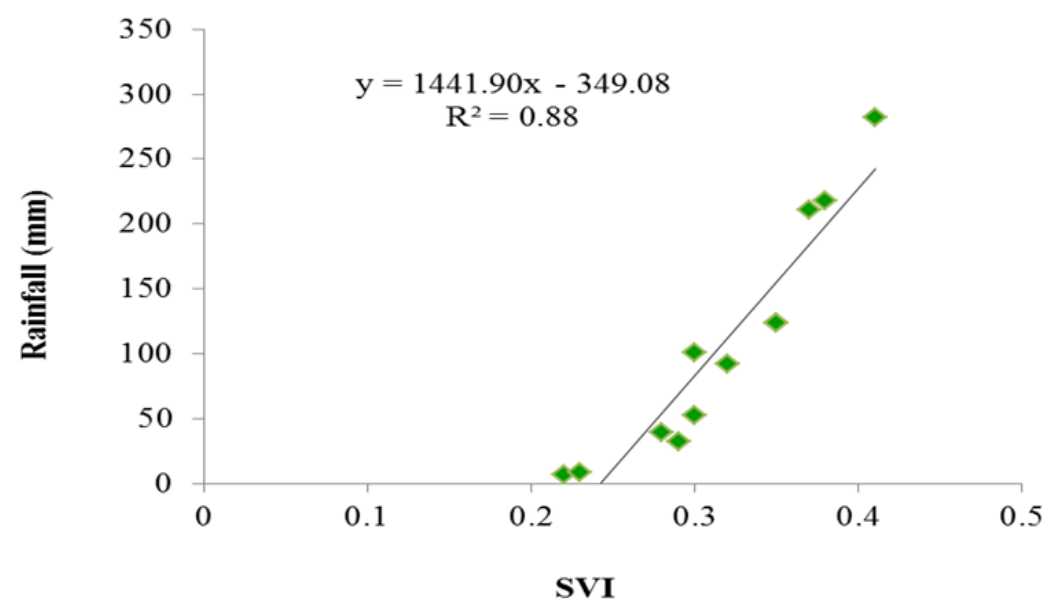

Fig. 9. Relationship of SVI and rainfall data in 2015

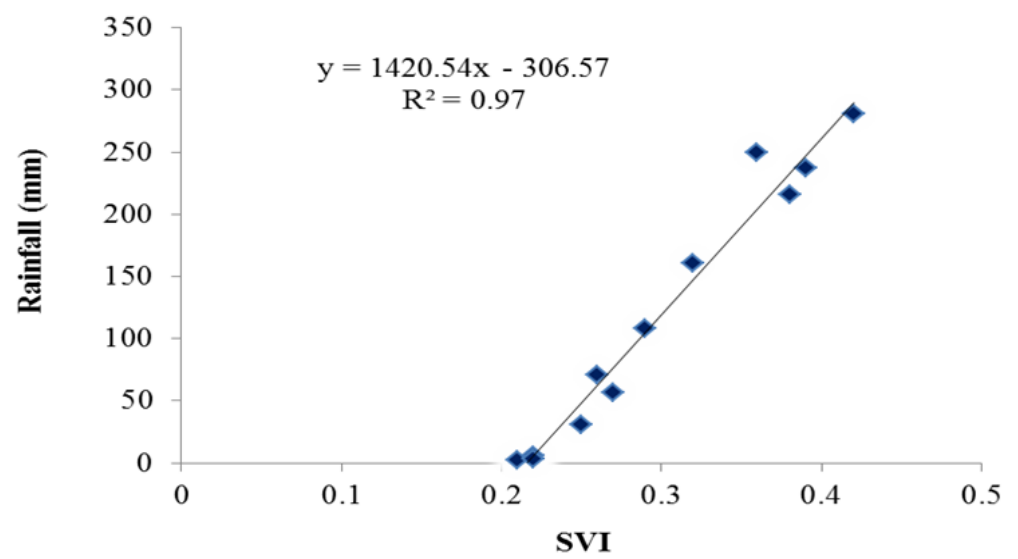

Fig. 10. Relationship of SVI and rainfall data in 2016

\section{CONCLUSIONS AND DISCUSSION}

According to the analysis of the means of the SVI in this study, it was discovered that the closer the SVI accessed to 0, the more severe the drought. In contrast the closer the SVI accessed to 1, the higher the moisture increased. When the analysis results of the SVI in all three years were calculated into the percentages of the areas, it was found that the maximum drought was in 2016, with the drought areas at $91.29 \%$ or $76,955.30 \mathrm{~km}^{2}$. The second one was in 2014 , with the drought areas being $90.99 \%$ or $76,702.41 \mathrm{~km}^{2}$, followed by 2015 , in which the drought areas was $89.21 \%$ or $75,201.91 \mathrm{~km}^{2}$, respectively. The statistical relationship analysis between the SVI and the rainfall unveiled a high conformity. This could be noticed from the coefficient of determination $\left(\mathrm{R}^{2}\right)$. All three years possessed the coefficient of determination $\left(R^{2}\right)$ values close to 1 . To clarify, in $2014, R^{2}=0.83$; in $2015, \mathrm{R}^{2}=0.88$; and in $2016, \mathrm{R}^{2}=0.97$. Furthermore, it was proved that high rainfall 
affected the high SVI. On the contrary, low rainfall affected a low SVI. However, the SVI change might be slightly slower than the rainfall because of the development of vegetation after there was sufficient water for growth.

In addition, the results of this research were compared with other similar research articles. For example

1) A five-year analysis of MODIS NDVI and NDWI for grassland drought assessment over the central Great Plains of the United States by Gu et et al., 2007. The results showed that MODIS data, after analysis by Normalized Difference Vegetation Index (NDVI), Normalized Difference Water Index (NDWI) and Normalized Difference Drought Index (NDDI), were able to identify grassland drought.

2) A combination of meteorological and satellite-based drought indices in a better drought assessment and forecasting in Northeast Thailand by Thavorntam et al., 2015. The results showed that Terra MODIS VIs Product after analysis by Vegetation Condition Index (VCI) can be applied to assess drought severity and drought-affected areas for efficient drought management and planning.

3) Drought Detection by Application of Remote Sensing Technology and Vegetation Phenology by Uttaruk \& Laosuwan, 2017. This research indicates that, an analysis Landsat 8 satellite data with Vegetation Condition Index (VCI) can be identified drought area from vegetation phenology.

The results of these three articles were similar to this present study of which the technique and the results should be regarded as the logical analysis and examination criteria of the drought areas in the Northeastern region of Thailand. Moreover, they can be applied for quick and reliable examination as well as future estimation of drought areas. Furthermore, the related government agencies and private sector can utilize this technique to analyze any expected drought areas, so to obtain the results for writing future sustainable drought prevention and mitigation plans in other areas of Thailand.

\section{R E F E R E N C E S}

Costea, G., Haidu, I. (2010). Detection of recent spatial changes regarding landuse in small basins from the Apuseni Natural Park. Geographia Technica, 5(2), 11-27.

Costea, G., Serradj, A., Haidu, I. (2012). Forest cartography using Landsat imagery, for studying deforestation over three catchments from Apuseni mountains, Romania. In: Advances in Remote Sensing, Finite Differences and Information Security. Proceedings of the 8th WSEAS International Conference on Remote Sensing, (REMOTE' 12), Prague, Czech Republic, September 24-26, 2012, WSEAS PRESS. ISBN: 978-1-61804-127-2, 109-114.

Gessner, U., Naeimi, V., Klein, I., Kuenzer, C., Klein, D. \& Dech, S. (2013).The relationship between precipitation anomalies and satellite-derived vegetation activity in Central Asia. Global and Planetary Change, 110, 74-87, 2013.

Gomasathit, T., Laosuwan, T., Sangpradit, S. \& Rotjanakusol, T. (2015). Assessment of Drought Risk Area in Thung Kula Rong Hai using Geographic Information System and Analytical Hierarchy Process. International Journal of Geoinformatics, 11 (2), 21-27.

Gu, Y., Brown, J.F., Verdin, J. P. \& Wardlow, B. (2007). A five-year analysis of MODIS NDVI and NDWI for grassland drought assessment over the central Great Plains of the United States. Geophysical Research Letters, 34(6), 1-6

Kogan, F., \& Guo, W. (2015). Agricultural Drought Detection and Monitoring Using Vegetation Health Methods. In Remote Sensing of Water Resources, Disasters, and Urban Studies; Thenkabail P.S., Ed.; CRC Press: Boca Raton, FL, USA, 339-348, 2015. 
Laosuwan, T., Sangpradid, S., Gomasathit, T. \& Rotjanakusol, T. (2016). Application of Remote Sensing Technology for Drought Monitoring in Mahasarakham Province, Thailand. International Journal of Geoinformatics, 12(3), 17-25.

Malo, A. \& Nicholson, S. E. (1990). A Study of Rainfall and Vegetation Dynamics in the African Sahel Using Normalized Difference Vegetation Index. Journal of Arid Environments, 19, 1-24.

Mongkolsawat, C., Thirangoon, P., Suwanwerakamtorn, R., Karladee, N., Paiboonsak, S. \& Champathet, P. (2001). An evaluation of drought risk area in Northeast Thailand using remotely sensed data and GIS. Asian Journal of Geoinformatics, 1, 33-44.

Mongkolsawat, C., Wattanakij, N., Kamchai, T., Mongkolsawat, K. \& Chuyakhai, D. (2009). Exploration of Spatio-Temporal Drought Patterns using Satellite-Derived Indices for Crop Management in Northeastern Thailand. Proceedings of the 30th Asian Conference on Remote Sensing China. 18-23 October 2009. Beijing, China.

Nistor, M.M., Man, T.C, Benzaghta, M.A., Nedumpallile Vasu, N., DezsiI, Ş. \& Kizza, R. (2018). Land Cover and Temperature Implications for the Seasonal Evapotranspiration in Europe. Geographia Technica, 13(1), 85-108.

Park, J., Kim, K. \& Choi, Y. (2008). Application of Vegetation Condition Index and Standardized Vegetation Index for Assessment of Spring Drought in South Korea. IGARSS 2008 - 2008 IEEE International Geoscience and Remote Sensing Symposium, Boston, MA.

Furtuna, P., Haidu, I., Alexe, M., Holobaca, I. (2015) Change detection in the Cluj forest district, using remote sensing and GIS application. Environmental Engineering and Management Journal, 15 (6), 1361-1367.

Furtuna, P., Haidu, I., Maier, N., (2018) Synoptic processes generating windthrows. A case study in the Apuseni mountains (Romania). Geographia Technica, 13(2), pp. 52-61.

Peters, J.A., Walter-Shea, E.A., Ji, L., Andres, V., Michael, H. \& Svoboda, M.D. (2002). Drought Monitoring with NDVI-Based Standardized Vegetation Index. Photogrammetric Engineering \& Remote Sensing, 68(1), 71-75.

Seekaw, A., Mongkolsawat, C. \& Suwanwerakamtorn, R. (2014). Using standardized vegetation index to assess drought areas in Northeast Thailand. Journal of Remote Sensing and GIS Association of Thailand, 15 (2), 25-38.

Thavorntam, W., Tantemsapya, N. \& Armstrong, L. (2015). A combination of meteorological and satellite-based drought indices in a better drought assessment and forecasting in Northeast Thailand. Natural Hazards, 77(3), 1453-1474.

Tucker, C.J. (1979). Red and Photographic Infrared Linear Combinations for Monitoring Vegetation. Remote Sensing of Environment, 8(2), 127-150.

Uttaruk, Y. \& Laosuwan, T. (2017). Drought Detection by Application of Remote Sensing Technology and Vegetation Phenology. Journal of Ecological Engineering, 18(6), 115-121.

Vrieling, A., Meroni, M., Shee, A., Mude, A. G., Woodard, J., de Bie, C. A. J. M. \& Rembold, F. (2014). Historical extension of operational NDVI products for livestock insurance in Kenya. International Journal of Applied Earth Observation and Geoinformation, 28, 238-251.

Wang, J., Rich, P.M. \& Price, K.P. (2013). Temporal Responses of NDVI to Precipitation and Temperature in the Central Great Plains, USA. International Journal of Remote Sensing, 24(11), 2345-1364.

Wattanakij N. \& Mongkolsawat C. (2008). Drought Detection in Northeast Thailand using Standardized Vegetation Index of Multi-Temporal Satellite Data, In: Proc. 4th Environment Naresuan Conference, Naresuan Univeristy, Thailand, 206-215.

Wu, J., Zhou, L., Liu, M., Zhang, J., Leng, S. \& Diao, C. (2013). Establishing and Assessing the Integrated Surface Drought Index (ISDI) for Agricultural Drought Monitoring in Mid-eastern China. International Journal of Applied Earth Observation and Geoinformation, 23, 397-410.

Zhang, Y., Peng, C., Li, W., Fang, X., Zhang, T., Zhu, Q., Chen, H. \& Zhao, P. (2013). Monitoring and estimating drought-induced impacts on forest structure, growth, function, and ecosystem services using remote-sensing data: Recent progress and future challenges. Environmental Reviews, 21, 103-115. 